\title{
NET-ATIVISMO, COLABORAÇÃO E APRENDIZAGEM: Apontamentos etnográficos $s$ obre a experiência da rede fora do eixo
}

Eduardo S. Junqueira Tatiana Paz ${ }^{(*)}$

Dentre os diversos fenômenos emergentes que se constituem hoje nas redes telemáticas, os novos processos de aprendizagem sugerem otimismo e dúvida. Como se aprende em redes conectivas e interativas? Para além dos muros da escola e da educação formal, os sujeitos se encontram e se perdem no ciberespaço, ampliando as possibilidades de trocas comunicativas e da tessitura de novos saberes ao instituírem novas formas de participação social e ao se engajarem em inusitadas arquiteturas de fluxos informativos.

No cenário pós-manifestações de junho de 2013, busca-se compreender processos que articulam redes, ativismo, mídias e (novas) formas de aprender. Este artigo apresenta aproximações etnográficas, a partir de trabalho de campo, sobre o engajamento de ativistas em rede da Fora do Eixo (FdE) da casa Nordeste em processos de aprendizagem. O mapeamento se centrou nos processos nos quais integrantes da FdE exploraram novas possibilidades da conectividade em rede e das mídias para a tessitura de um ativismo que enseja arranjos sociais abrangentes dos diversos aspectos da vida desses integrantes e novas conformações políticas.

A análise dos processos foi balizada por autores que têm buscado teorizar a natureza e as práticas dos movimentos sociais em rede (CASTELLS, 2013; DI FELICE, 2013) e novos processos de aprendizagem em rede (SIEMENS, 2006), buscando-se compreender como os sujeitos constroem e vivenciam essas (novas) formas de aprender com e no net-ativismo.

\section{NET-ATIVISMO E REDES DE COLABORAÇÃO}

Ao longo da história, os movimentos sociais se constituíram como importantes mobilizadores de mudanças sociais. Impulsionados por uma crise relacionada à forma como os

\footnotetext{
(*) Eduardo S. Junqueira. Doutor em Educação. Professor do Programa de Pós-Graduação em Educação da Universidade Federal do Ceará. E-mail: eduardoj@virtual.ufc.br.
}

Tatiana Paz. Doutoranda em Educação Brasileira pela Universidade Federal do Ceará. E-mail: tatianaspaz@ gmail.com. 
governantes conduzem e assumem os interesses de ordem pública, as pessoas buscam autonomamente defender as suas demandas. De acordo com Castells (2013), as redes horizontais de comunicação multidirecional e interativa na internet - principalmente as atuais redes de comunicação sem fio - se tornaram o novo contexto em que os movimentos sociais do século XXI se constituem.

Segundo Di Felice (2013), o termo ciberativismo teve origem na década de 1990, com o advento das tecnologias digitais e se manifestava através de diferentes movimentos marcados pela difusão de informações na rede com objetivo, por exemplo, de boicotar o consumo de determinados produtos e também de realizar ocupações. De acordo com o autor, esse tipo de ativismo midiático encontrou nas tecnologias de comunicação uma aliada valiosa para o fortalecimento das organizações de maneira local e global, na coordenação de campanhas e protestos e difusão de informações, denúncias e petições.

Porém, Di Felice (2013) destaca que

o que constitui a característica própria do ciberativismo, ou ativismo online, não se resume à simples incorporação da internet aos processos comunicativos do ativismo, mas inclui a forma como essa tecnologia comunicativa transformou substancialmente o próprio ativismo e os conceitos de participação, espaço democrático, identidade coletiva e estratégia política. (p. 54)

O contexto do ciberativismo possibilitou o fortalecimento de uma identidade cidadã global, habitante das redes digitais, que não nega a diversidade local e cujas pautas reivindicatórias e de ação avançam na direção do atendimento das necessidades comuns (DI FELICE, 2013).

$\mathrm{Na}$ atuação ciberativista "o uso das redes de comunicação da internet e dos telefones celulares é essencial, mas a forma de conectar-se em rede é multimodal. Inclui redes sociais on-line e off-line, assim como redes preexistentes e outras formadas durante as ações do movimento" (CASTELLS, 2013, s/p) .

As tecnologias possibilitam também a formação de redes internas ao movimento, com outros movimentos ao redor do mundo, com as mídias e com a sociedade em geral. Nesse sentido, de acordo com Castells (2013), as tecnologias são significativas por fornecerem a plataforma para uma prática continuada e que tende a se expandir, evoluindo com a mudança de formato do movimento. Esse contexto é a base da atuação do coletivo Fora do Eixo que atua de forma ativista em rede, utilizando artefatos tecnológicos na articulação de causas culturais e políticas. 


\subsection{A rede Fora do Eixo}

Ao buscar definir os contornos da FdE, Savazoni (2014) refere-se a um vídeo compartilhado no Youtube pelo coletivo em 2012 e intitulado "Fora do Eixo é Confundir" e que apresenta uma série de termos associados aos fazeres do coletivo, dentre eles cultura, música, cinema, universidade, teatro, meio ambiente, dança, tradição, coletivo, articulação, cumplicidade, conexão, exu, prática, pensar, devir, rede e militância.

Trata-se de uma rede ampla, autônoma e descentralizada que se articula em torno de produção cultural (particularmente através de festivais de música "autoral” alternativa aos esquemas das grandes gravadoras) e mobilização política (notadamente na defesa de causas sociais ditas polêmicas, como a defesa dos direitos das minorias e outras em geral associadas aos movimentos de esquerda). Do ponto-de-vista da ação, a FdE se intitula uma organização de ativismo digital, conferindo destaque à comunicação na atuação política da rede, através da formação de quadros e da utilização de redes sociais e diversos aplicativos de comunicação hoje disponíveis, bem como da articulação e participação em manifestações e outros eventos de rua de caráter político e cultural.

A Carta de Princípios da rede FdE, no que se refere ao tópico sobre "formação e conscientização", destaca a ocorrência de renovados processos de formação dos participantes, a criação de ferramentas para a realização desses processos com base no conhecimento cooperativo, solidário e coletivo e na busca de competência técnica dos setores produtivos no desenvolvimento de suas ações. O principal eixo de formação do movimento é a Universidade Fora do Eixo, como será detalhado a seguir.

\subsubsection{A Universidade Fora do Eixo}

A Universidade reúne experiências associadas a processos de formação e aprendizagem dos diversos coletivos associados, nomeadas "tecnologias aplicáveis". Os participantes são nomeados "viventes" e integram variadas modalidades de eventos presenciais e online com metodologias diversas que abrangem desde a realização de "colunas" (viagens de grupos a regiões remotas do país) à participação no desenvolvimento de conteúdos com a tecnologia wiki e de banco de dados.

Os atores da rede se aglutinam em torno das "tecnologias" desenvolvidas no contexto de ações político-culturais da FdE, dentre elas as "casas", que se configuram como "campus permanentes", e os eventos, articulados como "campus temporários" onde ocorrem "vivências" (estágios em projetos de mídia livre como a NINJA e a PosTV), construção e compartilhamento de "tutoriais" e cartilhas para oficinas on-line e presenciais, interações em listas de discussão (conhecimentos sobre artefatos digitais e modos contextualizados de uso). 
Segundo Savazoni (2014),

as soluções criadas por cada um dos agentes que integram o FdE são parte daquilo que seus integrantes chamam de TECs, uma abreviação para tecnologias sociais. [...] Normalmente, esses conteúdos são compartilhados não apenas com os membros da rede, mas por meio de canais abertos na internet. Essa logica é inspirada na cultura [de compartilhamento] do software livre. (p. 26).

Parte do conhecimento sobre net-ativismo desenvolvido no contexto da rede FdE se encontra reunido em "cartilhas" em formato digital disponibilizadas em rede pelo coletivo e seus parceiros, totalizando cerca de 100 títulos. ${ }^{\mathrm{i}}$ A Universidade disponibiliza pelo menos duas cartilhas sobre cobertura colaborativa, prática característica do coletivo.

Uma delas apresenta de forma sucinta o que é a cobertura colaborativa e visa permitir que novos integrantes da rede e de coletivos parceiros possam implantar a metodologia localmente. O material inclui um passo-a-passo sobre como desenvolver a metodologia, com links para planilhas relacionadas e se divide nos tópicos: mapeamento de agentes, elaboração de dinâmicas de grupo, formação, produção, pós-produção. Outra cartilha, mais detalhada, baseada em trabalho de curso de graduação de um parceiro, constitui um "manual de planejamento" que fornece subsídios para uma boa compreensão de todo o processo e sua prática.

As práticas de cobertura colaborativa são muito caras à FdE porque permitem viabilizar a execução de eventos variados a baixo custo e também criam diversas oportunidades para trocas e aprendizagens entre os participantes, sustentando-se pelas potencialidades comunicativas das redes temáticas e seus dispositivos e na disponibilidade dos atores em colaborar com as iniciativas da FdE. Em parte, "a cobertura colaborativa tem sua genealogia quando determinado acontecimento público é transformado em fato jornalístico pelo trabalho de engajamento coletivo dos perfis nas redes sociais" (MALINI \& ANTOUN, 2013, p. 247). O participantes difundem ao vivo, via streaming, material escrito, fotográfico e audiovisual, ampliando a escala de abrangência em termos de público e de registros. Os materiais difundidos são reunidos por tags que organizam um grande acervo de notícias sobre um mesmo acontecimento.

Essas cartilhas, suas temáticas e suas formas de elaboração, circulação e utilização apreendem significativas características dos propósitos e do modus operante da Universidade Fora do Eixo: o desenvolvimento de processos de formação aberta, continuada e descentralizada, com tempos e formatos variados, voltadas à prática do ativismo em rede e se beneficiando de saberes diversos em constante atualização a partir de princípios colaborativos. 


\subsection{Aprendizagem colaborativa e ações ativistas em rede}

As ações ativistas promovidas pelos coletivos em rede possibilitam trocas comunicativas intensas do ponto de vista da construção e produção de conteúdos, assim como das interações com aqueles que interagem com as informações que circulam através destes grupos. A cobertura colaborativa é um exemplo de como a experiência ativista envolve processos coletivos de produção de conteúdos que proporcionam espaços de aprendizagem aos diferentes atores dessa rede.

As possibilidades autorais conferidas pela $W e b$ permitiram a formação de cibercomunidades nas quais os indivíduos interagem de forma colaborativa ao compartilhar suas autorias - imagens, vídeos, textos, etc. Estas trocas comunicacionais em rede vivenciadas de forma coletiva podem proporcionar processos de aprendizagem colaborativa (OKADA, A.; OKADA, S.; SANTOS, E., 2008).

O formato da cobertura colaborativa, por exemplo, se diferencia da forma em que opera a imprensa tradicional por ser produzida de modo descentralizado pelos nós da rede e por ser nucleada por uma tag que concentra grande quantidade de conteúdos sobre um mesmo acontecimento. A imprensa tradicional busca criar uma versão do "todo" de um acontecimento, oferecendo uma visão panorâmica e centralizada dos fatos.

Segundo Pretto (2010), “a juventude apropriou-se das tecnologias e as transformou completamente, de um meio meramente receptor de informações para um meio de expressão de ideias e de manifestação da pluralidade e de cidadania" (p. 309). Os dispositivos móveis passaram a ser usados como elementos estruturantes de outra comunicação, alimentando, no ato, em tempo real, os sites de redes sociais com informações que efetivam novas formas de produção colaborativa de conhecimento livre que, segundo o autor, são experiências fundamentais para pensar a educação numa perspectiva colaborativa.

\section{CONSTRUINDO UM PERCURSO ETNOGRÁFICO DE PESQUISA}

O olhar etnográfico (GEERTZ, 1973) adotado na condução desta fase do estudo aqui apresentado buscou compreender o fenômeno investigado através da observação de práticas e eventos - em particular aqueles que se constituem no âmbito da aprendizagem - presentes no cotidiano das ações da rede $\mathrm{FdE}$, buscando situá-las junto às trajetórias pessoais dos seus participantes e de elementos dos contextos em que se constituem, pois "as esferas de influência mais amplas devem também ser consideradas ao se investigar circunstâncias mais específicas da 
cena local" (ERICKSON, 1986, p. 122, tradução nossa) sem se desconsiderar que as pessoas agem a partir de sua compreensão de seus mundos sociais locais (EMERSON et al., 1995).

Em suma, buscou-se compreender aspectos da complexidade do que os integrantes da rede sabem, compreendem, produzem e antecipam ao participarem ativamente do coletivo em que se inserem, documentando "perspectivas culturalmente construídas, interpretações e categorias utilizadas por membros do grupo em estudo para se dar sentido e categorizar seus conhecimentos e para guiar seu próprio comportamento" (WATSON-GEGEO, 1989, p. 580, tradução nossa), bem como possíveis relações entre práticas e eventos de aprendizagem ao ativismo em rede, pois Miller e Goodnow (1995) argumentam que os "pesquisadores buscam compreender não somente o significado que as práticas possuem para as pessoas mas também o seu grau de comprometimento ou de investimento nelas" (p. 10) e as razões associadas a elas.

O processo de coleta de dados buscou preservar certo distanciamento crítico em relação ao objeto de estudo e compreendeu visitas semanais durante um mês à casa da FdE em Fortaleza, participação em reuniões do coletivo para a organização de um evento de revitalização do centro da cidade, acompanhamento das trocas de mensagens, links e arquivos realizadas em quatro chats da FdE em um aplicativo para dispositivos móveis, coleta de materiais diversos - em particular aqueles relacionados à Universidade Fora do Eixo - e o acompanhamento das interações que ocorreram no âmbito de uma formação sobre produção vídeo realizada na universidade. No que se refere aos chats, buscou-se documentar as trocas comunicativas e compreender como se dão as relações neste espaço, ou seja, os "modos de socialização" (RIFIOTIS, 2010) dos participantes.

A fim de documentar a perspectiva dos participantes, foram também realizadas entrevistas semiestruturadas em profundidade, documentadas em áudio, com dois integrantes que participam da rede há pelos menos três anos, com o objetivo de compreender elementos centrais identificados durante as observações a partir da visão desses integrantes, que se dispuseram a nos relatar ainda suas vivências na FdE e suas ideias sobre ativismo em rede e a formação como aprendizagem em rede.

Os resultados dessas observações, apresentados no próximo tópico deste artigo, seguiram uma linha de tratamento analítico dos dados coletados que busca compreender, a partir das nuances presentes nas falas e nas ações dos informantes, como se constitui seu engajamento no ativismo em rede e na FdE, e suas visões sobre processos, práticas, eventos e experiências vivenciadas por eles nestes contextos, particularmente aqueles relacionados à aprendizagem. 


\section{APRENDIZAGEM E ATIVISMO}

Este tópico divide-se em dois sub-ítens em que serão apresentadas e detalhadas falas e ações dos informantes relacionadas aos seus modos de vivência e de socialização do ativismo, particularmente no que se refere às suas trajetórias pessoais, seu engajamento e suas ações de ativismo da rede FdE e suas participações em processos de aprendizagem nestes contextos.

\section{Aprender como uma experiência de vida ativista}

Os processos de aprendizagem observados e relatados pelos informantes da pesquisa se constituem na prática militante desses, prática a que foram levados por questões de foro pessoal, relacionadas às suas identidades e suas visões sobre como transformar a realidade que os cerca. $\mathrm{O}$ informante 1 (que doravante será identificado pelo nome fictício de Carlos) associou, dentre outros motivos, sua entrada na FdE como um processo de descoberta pessoal de sua condição de minoria como homossexual e de defesa dos direitos dessa e de outras minorias.

[...] Eu não era envolvido com nada antes de entrar no FdE. Sou assumido homossexual desde os 15 anos, nunca tive uma luta com ninguém, nunca fui pra uma passeata. [...] Então, eu vim me reconhecer como pessoa e como agente dentro de um sistema inteiro há 3 anos atrás quando eu entrei pra o FdE. Então foi um processo de conhecimento de mim, não do outro.

Soma-se a esse traço central de sua identidade, a crença dele em ações compartilhadas e solidárias, tendo relatado experiências de descobertas dessas novas formas de viver como fatos marcantes para sua inserção na FdE. Para Carlos, o contato com o ativismo de outros integrantes do coletivo mobilizou questionamentos sobre a sua contribuição enquanto sujeito em pautas como a sexualidade. Diante da experiência dos seus pares, entendeu que o ativismo era uma prática que poderia dar voz às suas inquietações.

[...] passei um mês e fiz vivência, descobri que a casa não era só uma casa, era uma galera que tinha um movimento ativista, [...] e comecei a me perguntar “o que eu fazia como gay?" [...] Isso começou a gerar algumas ações, ficava emocionado, comecei a entender que aquilo ali era fato e que eu precisava participar também, até pra ter voz e pra poder falar aquilo tudo que eu achava, tudo que já estava aparecendo também de questionamento na minha cabeça e daí comecei a participar de atos.

A fala de Carlos indicou que a sua prática ativista possui dimensões afetiva e política que estão imbricadas no seu modo de vida. As questões da sua subjetividade alcançam uma dimensão política no fazer ativista, que por sua vez encontra sentido na sua própria história de vida. Nesse sentido, a formação proporcionada pela vivência com a FdE é vista como uma formação humana para Carlos, na qual pôde desconstruir ideias e se engajar como ativista. A experiência relatada por 
ele mostrou que a sua aprendizagem se processa em experiências de vida que desafiam, emocionam, e provocam novas produções de sentido para a ação social.

Percebi que não fazia somente o mídia NINJA, eu me formava como gente, eu nunca tinha feito uma ocupação na minha vida, [...] fui quebrando barreiras o tempo todo, quando fui pra minha primeira ocupação eu passei a noite inteira chorando, não consegui fazer nenhuma foto...fiquei totalmente emocionado com tudo aquilo que estava vendo, uma galera que não tinha comida em casa, juntaram tudo e preparou um jantar pra mim [...] Então, o FdE e o mídia NINJA foi muito uma transformação minha, uma rede que me acolheu e me abriu os braços, se você quer aprender, está aqui e ninguém é obrigado a nada, se eu quiser eu saio. Pretendo continuar por causa dessa formação totalmente humana que eu tô recebendo...

No que se refere mais especificamente aos sentidos e aos processos de aprendizagem na FdE, a informante 2 (que doravante será identificada pelo nome fictício de Cláudia), ao relatar sobre sua vida ativista atuando em diferentes "frentes" do coletivo, ressaltou inicialmente um momento de vivência e aprendizagem sobre o próprio ativismo da FdE indicado na sua fala:

passei por várias frentes, acompanhei parte de partidos, de articulação e mobilização, entrar em contato com parceiros... Faço parte da mídia, que é esse processo de divulgação em rede, faço peças de design, tem a parte do banco de sustentabilidade que eu ajudo também. Eu consigo ir em todas as frentes e é uma coisa que é da rede - de todo mundo conseguir caminhar.

Além de ressaltar essa dimensão abrangente da aprendizagem na FdE, permitindo-lhe vivenciar e atuar de formas variadas e a desenvolver uma visão mais integradora da rede FdE, Cláudia refletiu de forma crítica sobre vivências de aprendizagem quando cursou o bacharelado em Pedagogia:

Na universidade você chega com uma ideia e as pessoas ficam com medo de que a sua ideia seja roubada, sabe? [...] Ah! Vamos pensar todo mundo junto, entendeu? [...] Então tem esse campo de disputa individual. A gente tem um campo de disputa coletiva, então ir pra rua foi um campo de disputa coletiva e aí uma pessoa sozinha não consegue fazer.

A integrante da FdE contrastou sua formação universitária com as vivências na "Rede" nas quais diz possuir mais liberdade para se colocar com sua identidade e seus interesses "reais" a serviço do ativismo e da solidariedade em rede. Cláudia se define como uma autora, ativista, protagonista situada em um coletivo "orgânico" ao compartilhar causas e modos de vida comuns.

O protagonismo também foi um elemento destacado por Carlos no seu fazer ativista que, segundo ele, contrasta com as práticas na universidade:

Sair da minha caixinha é sair do meu comodismo mesmo. É daquele cômodo de que tudo que o povo me diz eu tenho que fazer. Será que eu não posso pensar algo mais? Eu tenho direito de pensar, eu tenho direito de agir?. 
O distanciamento, de acordo com Cláudia, entre os processos de aprendizagem que acontecem na universidade e na FdE reside também na existência de um "desejo comum" que mobiliza os sujeitos dessa rede a agir de forma colaborativa a fim de constituírem o ativismo na FdE. Ela afirma que:

A gente tem tesão no que a gente faz. Se não tem, acaba se tornando um fardo. E às vezes pode acontecer isso na universidade [...] O que a gente está fazendo aqui a gente faz, porque a gente gosta, porque a gente quer e a gente quer que esse trabalho seja visto por outras pessoas, e é de forma colaborativa.

A fala de Cláudia indicou que, para ela, a sua mobilização define como ela vivencia as situações de aprendizagem. Aprender exclusivamente por obrigação dificulta o percurso formativo, segundo ela. $\mathrm{O}$ discurso de Carlos indicou que o prazer encontrado no ativismo tem relação com o tipo de ser humano que você projeta de si. No seu caso, um tipo de sujeito participativo, revolucionário:

O FdE é aberto pra escolher aquilo que tem pauta, tem voz, aquilo que você consegue. Pode ficar em casa fazendo rede, ligando, mobilizando. Você ir pra rua era excitante como ser humano, pela pauta, [...] por tudo, me sentia humano, participativo, revolucionário, sabia que o que estava fazendo era algo de útil pra o mundo.

Nesse movimento de ativismo percebemos, de acordo com a fala dos informantes, que as ações nas quais os sujeitos se envolvem são aquelas com as quais se sentem confortáveis - seja por habilidades ("aquilo que você consegue") ou por desejo ("porque a gente quer"). Esse conjunto de fatores encontra-se no cerne do engajamento nas práticas constituídas na FdE.

As práticas colaborativas na FdE se constituem simultaneamente 1) como forma de compartilhamento, de trocas comunicativas múltiplas e diversas que realizam em si o fazer ativista articulado pela rede FdE e 2) se abastecem disso (do modo de ser ativista e das trocas comunicativas) para se constituírem de fato como colaborativas e produzirem engajamento real dos participantes.

O processo de aprendizagem vivenciado de forma colaborativa na FdE pode ser aproximado àquele vivenciado na cultura Hacker:

O modelo aberto de aprendizagem dos hackers pode ser denominado de 'Academia da Rede'. Esse ambiente de aprendizagem, que está em um processo contínuo de evolução, foi criado pelos próprios aprendizes e possui muitas vantagens. No mundo dos hackers os professores -ou aqueles indivíduos que montam as fontes de informação -- são muitas vezes aqueles indivíduos que acabaram de aprender algo. (HIMANEN, p. 75). 


\section{Aprender em rede de forma colaborativa através de trocas comunicativas}

As práticas de aprendizagem vivenciadas por Cláudia na FdE estão relacionadas a experiências anteriores em família, mas também a um desejo de explorar possibilidades, desvendar algo ainda inexplorado, como ilustrado nesse trecho da fala em que relata como aprendeu a ser uma designer multimídia:

Pode ser online também, [utilizando] o Hangout, Skype, tela duplicada (risos), mas muito, passava vídeo, aí vai lá e mexe, entendeu? Assim, era do meu pai isso, o meu pai tinha isso, de você ir lá e fazer, a primeira vez que a gente teve um computador em casa foi aquele 486 barra Windows não sei o que (risos) e eu perguntei "pai, como vou fazer?" [Ele respondeu] "Taí minha filha, se mete e vai vendo." E se quebrar? "Não vai quebrar, mexe! Mexe nesse negócio e aprende como é que funciona, e faz" (risos). Então, assim, é ir lá e entender como é que funciona.

Essas experiências de caráter pessoal e de vivências em família indicam modos de fazer com os quais Cláudia se identificou e conectou ao ingressar na rede FdE:

[...] um dos meninos que era da comunicação e era jornalista do Coletivo teve que sair em cobertura [...] Eu falei: Ah gente, se alguém me ensinar, eu faço. [...] Aí me ensinaram, aí eu entrei em contato com a galera que já era da parte de comunicação da rede, eles me explicavam como era que funcionava: "oh, tem o plano de mídia aqui, tem o doc do plano de mídia, tem uma planilha pra você sistematizar tudo que você vai organizar, é legal você montar um cronograma pra soltar as atividades" e tudo mais. E aí a gente vai aprendendo.

Nas trocas comunicativas que se processam em rede entre integrantes da FdE (ver imagens 1 e 2) em geral se utiliza conhecimentos prévios (como a leitura das cartilhas e o uso de planilhas customizadas pelos coletivos), mas dúvidas e dificuldades são esclarecidas com os parceiros nos chats específicos. Essas trocas podem gerar novos momentos de aprendizagem ao longo da realização de uma ação ativista.

Imagem 1. Recorte de um chat da FdE no Telegram em que Carlos ensina um parceiro a utilizar um artefato tecnológico.

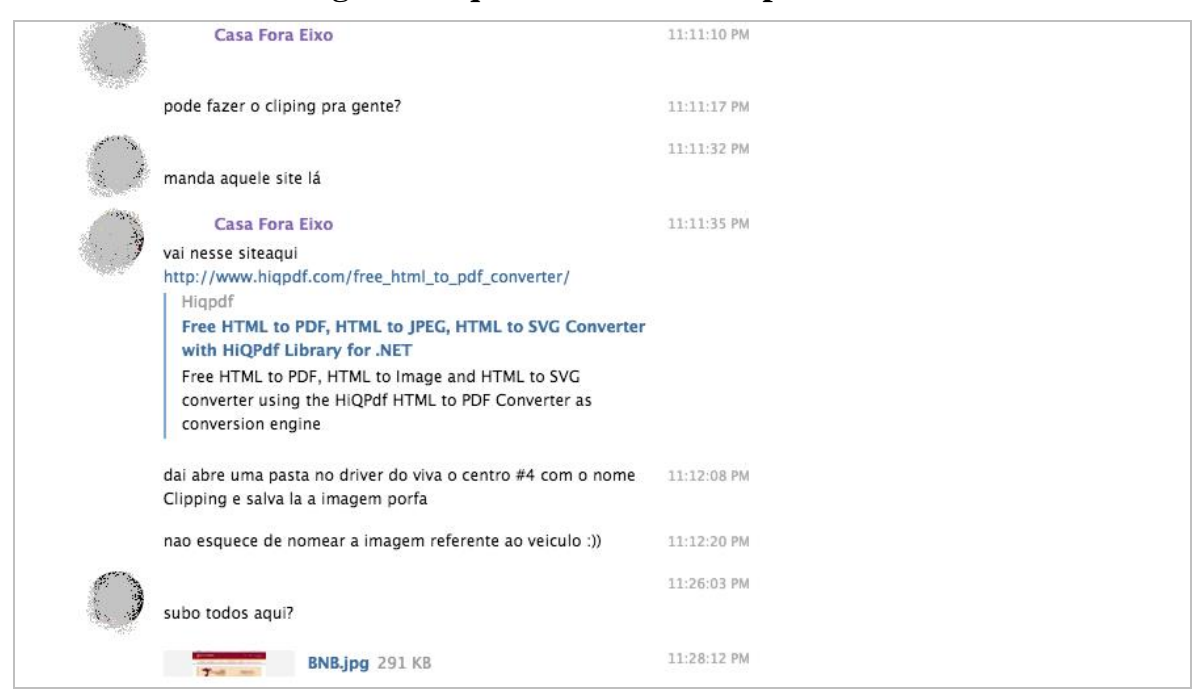


Trata-se de um processo de muitas idas e vindas, muitas trocas em rede, como indicou esse trecho da fala de Cláudia:

É isso, vai por esse caminho? E a pessoa devolve, acho que vai por esse caminho, precisa tentar explicar melhor essa parte e aí até ajuda com umas referências, como um professor faz orientando [...] E a gente está num processo de ter um gestor, você tá aprendendo com ele, e ele também aprende com você, porque às vezes dúvidas que você tem, ele também tem e vocês acabam trocando, trabalham juntos a dúvida e tudo mais.

Cláudia relata aspectos desse processo de trocas e de aprendizagem que podem ampliar o foco da aprendizagem:

Quando tá fazendo [uma tarefa] pode fazer pergunta também "gente, não está dando certo isso aqui", "ah gente, eu tentei botar esse triângulo aqui no meio da foto e não deu certo", "vamos, como é que usa?", aí acontece de mandar também outros links de referência, links de baixar fontes, links de estudo.

De acordo com a fala de Cláudia e Carlos, a aprendizagem colaborativa se constitui particularmente nos chats específicos e se beneficia de participantes mais experientes que operam resolvendo dificuldades surgidas durante a realização da tarefa.

As trocas realizadas entre os integrantes do grupo, de diferentes formações, se constituem em um espaço diverso de aprendizagem e possibilitam uma formação ampla, extrapolando a tradição da educação formal, e são tão ou mais eficientes que estas, na visão de Carlos:

Ah, a Cláudia não é designer formada, mas ela faz coisas de designer que várias pessoas que eu conheço, que é designer formado, e ela faz muito melhor. E aí? Saca? Mas como é que Cláudia aprendeu? Cláudia não sabe fazer, mas ela tá tirando dúvida com um monte de gente. Cláudia não aprendeu [a ser] designer na universidade. Ela aprendeu na rede, trocando com um monte de gente e vendo a galera fazendo.

A experiência de Cláudia, segundo a fala de Carlos, ilustra processos de aprendizagem que se constituem através da troca e do compartilhamento de saberes entre os participantes mais experientes e os menos experientes. Nesse contexto, integrantes da FdE experimentam suas habilidades sem necessariamente ter vivenciado um processo formal de aprendizagem e se engajam em atividades com as quais têm prazer em desenvolver e com isso se mobilizam em busca de novos saberes.

No cotidiano do movimento da FdE as interações são constantes e intensas. Há dezenas de chats temáticos nos quais os participantes articulam diversas proposições, abrangendo a sugestão de temas e atividades, e o apoio e orientação a ações que já se encontram em movimento. Esses chats funcionam também como um espaço de monitoramento e de articulação em tempo real de ações da 
FdE. Por exemplo, é através dos chats que se comunica aos integrantes da rede a publicação de conteúdos relacionados no Facebook, o que permite articular, potencializar e monitorar o fluxo e a progressão desses conteúdos na rede social.

Imagem 2: Recorte de um chat da FdE no Telegram sobre processo de divulgação de ações ativistas nas redes sociais.

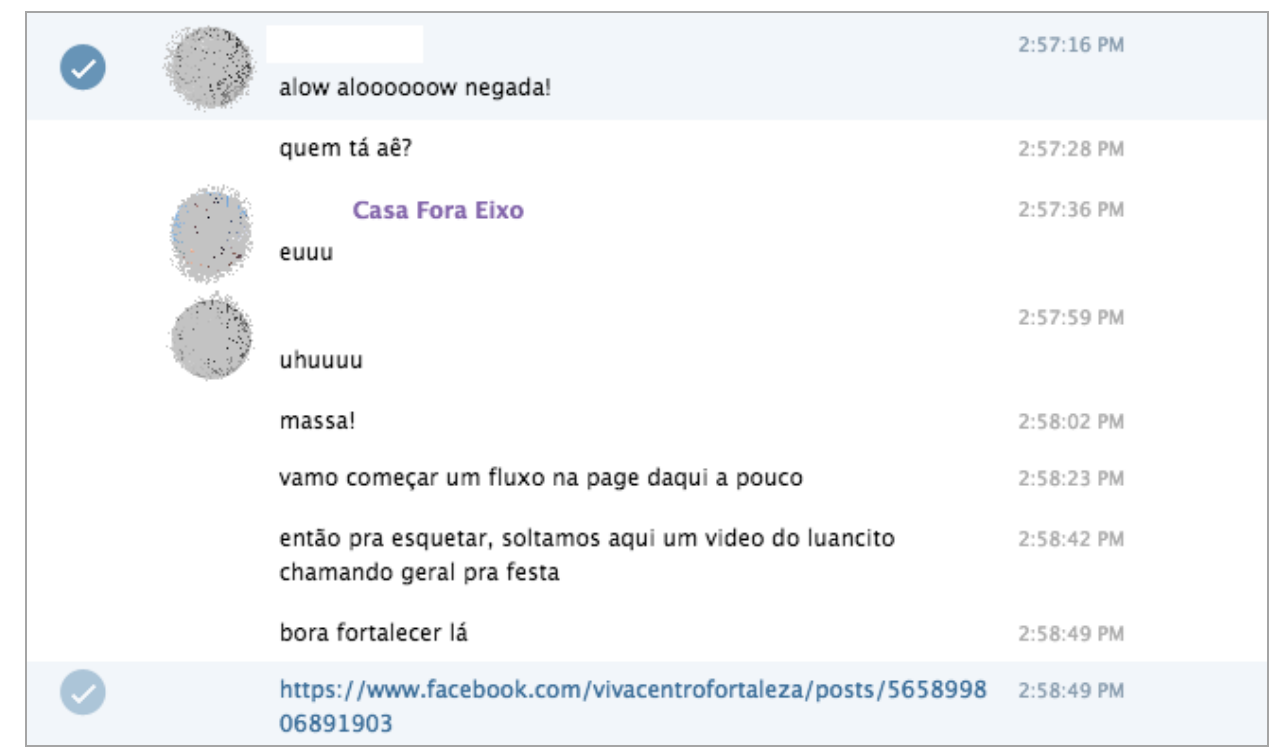

Os percursos vivenciados por Cláudia mostraram que o seu processo de aprendizagem é uma experiência que envolve erros e é sobretudo construída em rede com os pares, em sintonia com a prática de aprendizagem colaborativa dos hackers, na qual "todo material de estudo poderia ser livremente utilizado, criticado e desenvolvido por todos" (HIMANEN, 2001, p. 77). Os fluxos comunicacionais descritos pelos integrantes da FdE revelam um intenso processo de trocas que se realizam em rede e nas redes (Facebook, Google Drive, Telegram, etc.). Segundo eles, os fluxos de mensagens envolvem diferentes práticas e ações que abrangem, por exemplo, a logística de cobertura de um evento, o compartilhamento de links, de arquivos e de posts e conteúdos da próprio FdE a serem difundidos pelos pares nas suas redes.

Nesses percursos, os integrantes da FdE desenvolvem modos de fazer que são ensinados pelos próprios pares na rede e em rede. Esses processos de aprendizagem são pautados pelas demandas do grupo, desvinculados de processos formais de ensino, a exemplo do que acontece nas práticas de aprendizagem da cultura hacker em que "o processo típico de aprendizagem [...] começa quando um problema interessante é estabelecido" (HIMANEN, 2001, p. 74).

Dessa maneira, os processos de aprendizagem vivenciados pelos integrantes da FdE sustentam a proposição de Siemens (2006), que compreende que a educação formal não será suficiente para atender todas as necessidades de aprendizagem das pessoas e será complementada pela educação informal, que terá um papel muito importante na formação. Na FdE, em casos como 
a inserção de Cláudia no campo prático do design, a aprendizagem ocorreu para além dos processos de educação formal e se constituiu em rede, na relação com os pares, a partir de demandas postas pelo fazer ativista. Aproximam-se, também, da perspectiva de iniciação (MAFFESOLI, 2013) em que se constitui de forma horizontal, pelo compartilhamento de saberes em rede.

A experiência em rede vivenciada pelos integrantes da FdE se constitui em um processo de aprendizagem de natureza sociointeracionista, que se constrói por meio de uma relação de trocas entre o sujeito e meio social mediadas por ferramentas, instrumentos e tecnologias. Esse processo circular e abrangente, se constitui como um modo de ser e de estar no mundo que se conecta a uma vida ativista e que se justifica e se efetiva pelo investimento emocional dos participantes, a paixão, e o avanço do ativismo em rede (Imagem 3).

Imagem 3: $O$ caráter cíclico e holístico dos processos de aprendizagem na FdE

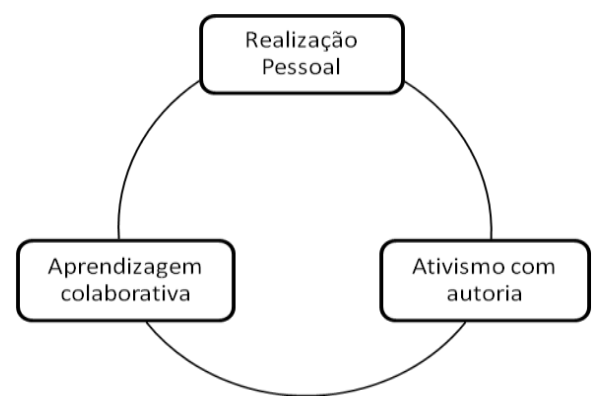

Portanto, no que se refere ao processo de aprendizagem, há duas esferas que se interpenetram: 1) a do movimento ativista, relativo ao viver o movimento e aprender a ser movimento social em rede; 2) a do aprender a realizar ações para o avanço do movimento, seja na área específica de atuação profissional (design, comunicação, mídias), seja do próprio movimento (banco sustentável, organização de congressos, etc.). Essas duas esferas de aprendizagem podem ser representadas pela expressão frequentemente utilizada pelos integrantes da FdE: a formação do cidadão multimídia, abrangendo ações nos campos da comunicação e do design (produção de peças gráficas, vídeos e participação em chats, compartilhamento de conhecimentos e fontes de referências).

A natureza do processo de aprendizagem colaborativa na FdE se aproxima do princípio da dádiva, incluindo contradições inerentes a este, pois tal princípio "é marcado por uma certa ambiguidade: gratuidade e retorno, interesse e desinteresse, liberdade e obrigação, desigualdade nas trocas, prazer em dar, espontaneidade, etc." (APGAUA, 2010, p. 84). Ressalta-se também que os processos mapeados guardam similaridades com formas de aprender em rede caracterizadas por Siemens (2006) dado seu caráter caótico, contínuo, cocriativo e complexo. E se constituem no 
marco da arquitetura das redes (WATTS \& MASON, 2011; BARABASI \& GONZÁLEZ, 2007), com ênfase aos aspectos da conectividade e da interação entre os sujeitos.

\section{CONCLUSÃO}

Neste estudo, a partir da perspectiva de Geertz (1989, apud MÁXIMO, 2010), buscou-se compreender a ocorrência dos processos de socialização e trocas simbólicas on-line (chats e redes sociais virtuais) e off-line (congressos anuais e ações de rua) dos participantes da FdE relacionadas a processos de aprendizagem. Os integrantes da FdE realizam práticas ativistas que abrangem ações diversas no campo político, cultural e midiático, fornecendo-lhes "modelos da cultura, mas também os formam, fornecendo modelos para a cultura" (MÁXIMO, 2010, p. 31, ênfase no original), o que se encontra no cerne do processo de aprendizagem colaborativa na perspectiva da cultura hacker.

A centralidade dos processos de aprendizagem vivenciados pelos integrantes da FdE nas práticas ativistas ganham especial destaque diante das muitas dificuldades enfrentadas pela educação formal em se inserir nas práticas correntes dos aprendizes imersos nas redes da cibercultura, vivenciando novas e inúmeras - e também, por vezes, frágeis - experiências de aprendizagem ao se conectarem em redes de trocas de saberes. Além disso, em face à conjuntura atual de ataques aos princípios democráticos no país, a rede FdE e seus integrantes articulam novas possibilidades de fazer político e de enfrentamento de instâncias tradicionais de poder que agregam uma não menos importante dimensão aos processos de aprendizagem documentos pelo estudo e analisados neste artigo.

Ainda que aspectos dos processos colaborativos e suas nuances aqui apresentados possam se beneficiar de maior aprofundamento descritivo e analítico, foi possível verificar a vitalidade e a centralidade dos processos coletivos de aprendizagem colaborativa e sua importante vinculação com as práticas ativistas em rede e com os elementos identitários da comunhão das histórias de vida dos informantes da FdE na construção de renovadas formas plurais, conectivas e heterogêneas do net-ativismo corrente.

Fases futuras deste estudo incluirão o acompanhamento e documentação de outros processos presenciais e on-line dos informantes, abrangendo suas interações on-line para se compreender como essas se relacionam com práticas ativistas em contextos ampliados, como os sites de informação e conteúdos diversos em redes sociais e outros espaços web. 


\section{REFERÊNCIAS}

APGAUA, R. O Linux e a perspectiva da dádiva. In: RIFIOTIS, T. (Org.) Antropologia no ciberespaço. Florianópolis: Editora da UFSC, 2010.

BARABÁSI, A.L.; GONZÁLEZ, M. Complex networks: From data to models. Nature physics, vol. 3, abr. 2007. Disp.:: <http://bit.ly/1YIbIMr>. Acesso: 20 maio 2016.

CASTELLS, M. Redes de indignação e esperança: movimentos sociais na era da internet. Trad.: Carlos A. Medeiros. Rio de Janeiro: Zahar, 2013.

DI FELICE, Massimo. Ser redes: o formismo digital dos movimentos net-ativistas. Revista Matrizes. São Paulo, n. 2, p. 49-71. 2013.

EMERSON, R.; FRETZ, R.; SHAW, L. Writing ethnographic fieldnotes. Chicago, IL: The University of Chicago Press, 1985.

ERICKSON, F. D. Qualitative research in education. In: WITTROCK, M.C. (Org.). Handbook of research on teaching. Washington: American Research Association, 1986.

GEERTZ, Clifford. The interpretation of cultures. New York: Basic Books, 1973.

HIMANEN, P. A ética dos hackers e o espirito da era da informação: a importância dos exploradores da era digital. Rio de Janeiro: Campus, 2001.

SIEMENS, G. Knowing Knowledge. 2006. Disp.: <http://www.elearnspace.org/KnowingKnowledge_LowRes.pdf>. Acesso: 20 out. 2015.

MÁXIMO, M.E. Da metrópole às redes sociotécnicas: a caminho de uma antropologia no ciberespaço. In: RIFIOTIS, T. (Org.) Antropologia no ciberespaço. Florianópolis: Editora da UFSC, 2010.

MAFFESOLI, M. Émotionnel e net-ativismo. I Congresso Internacional de Net-Ativismo, 2013. Disp.: <https:// www.youtube.com/watch?v=H4ZTpX4-Itc>. Acesso: out. 2015.

MILLER, P.J.; GOODNOW, J.J. Cultural practices as contexts for development. San Francisco, CA: Jossey-Bass Publishers, 1995.

OKADA, Alexandra; OKADA, Saburo; SANTOS, Edméa. Colearn: Ciberconferência e Cibermapeamento para Aprendizagem Colaborativa Aberta em Cibercomunidades. In: ASSOCIAÇÃO BRASILEIRA DE PESQUISADORES EM CIBERCUlturA. Anais do II Simpósio Nacional da Abciber. São Paulo: PUC-SP, 2008. Disp.:: <http://oro.open.ac.uk/41732/1/a14abciber2008.pdf>. Acesso: 20 maio 2016.

PRETTO, N. Redes colaborativas, ética hacker e educação. Educação em Revista. Belo Horizonte, v. 26 , n. 03 , p. 305-316, dez. 2010.

RIFIOTIS, T. Antropologia do ciberespaço: questões teórico metodológicas sobre pesquisa de campo e modelos de sociabilidade. RIFIOTIS, T. (Org.). Antropologia no ciberespaço Florianópolis: Editora da UFSC, 2010.

SAVAZONI, R. Os novos bárbaros: a aventura política do fora do eixo. Rio de Janeiro: Aeroplano, 2014.

WATTS, D.J.; MASONA, W. Collaborative learning in networks. PNAS-Proceedings of The National Academy of Sciences. Berkeley: vol. 109, n. 3, p. 764-769, 2011. Disp.: <http://research.microsoft.com/pubs/164568/ m_w PNAS 11.pdf>. Acesso: 20 maio 2016.

WATSON-GEGEO, K. Etnography in ESL: Defining the essentials. TESOL Quarterly, 22, p. 575-592, 1989. 


\section{RESUMO}

O artigo apresenta resultados de uma investigação etnográfica que buscou compreender processos de aprendizagem e colaboração relacionados ao net-ativismo (DI FELICE, 2013) e à rede Fora do Eixo (FdE). $O$ olhar etnográfico se norteou por um campo conceitual interdisciplinar que abrangeu os conceitos de Ciberpunk (LEMOS, 2004), a Ética Hacker (HIMANEN, 2001), as teorias das redes (CASTELLS, 2013, WATTS \& MASON, 2011; BARABASI \& GONZÁLEZ, 2007) e o Conectivismo (SIEMENS, 2006). A aprendizagem do e para o net-ativismo se constituiu nas trocas comunicativas dos cidadãos multimídia conectados em redes horizontais e interativas, conferindo-Ihe sentido e as retroalimentando, em um processo de validação e de iniciação (MAFFESOLI, 2013) ao se engajarem nas práticas insurgentes da FdE.

Palavras-chave: Net-ativismo; Aprendizagem; Colaboração; Rede Fora do Eixo.

\section{ABSTRACT}

The paper presents results of an ethnographic investigation that sought to understand learning and collaboration processes related to net-activism (DI FELICE, 2013) and the Fora do Eixo Network (FdE). The ethnographic study was guided by an interdisciplinary conceptual framework that included the concepts of Cyberpunk (LEMOS, 2004), Hacker Ethics (HIMANEN, 2001), the theories of networks (CASTELLS, 2013, WATTS \& MASON, 2011; BARABASI \& GONZÁLEZ, 2007) and Connectivism (SIEMENS, 2006). Learning to and from net-activism was constructed in communicative exchanges by multimedia citizens connected in horizontal and interactive networks. Learning provided meaning and reinforced the net-acitivism, in a process of validation and initiation (MAFFESOLI, 2013) for them to engage in FdE's insurgent practices.

Keywords: Net-activism; Learning; Collaboration; Fora do Eixo Network.

Submetido em: maio 2016 Aprovado em: Out. 2016

${ }^{\text {i }}$ Os autores deste estudo reconhecem relatos públicos associados ao caráter controverso de algumas práticas da FdE, particularmente sobre alinhamento com partidos políticos, financiamento público e relações trabalhistas. Essas questões extrapolam o escopo deste artigo, ainda que se reconheça suas implicações para algumas das proposições de cunho mais geral do coletivo, não diretamente relacionadas a processos de aprendizagem. 